\title{
Polyacrylamide and Water Quality Effects on Infiltration in Sandy Loam Soils
}

\author{
Husein A. Ajwa* and Thomas J. Trout
}

\begin{abstract}
Slow infiltration rates constrain effective and economical irrigation in some sandy loam soils in California. Polyacrylamide (PAM) has increased soil infiltration in some areas, especially in soils high in clay or silt. Field trials near Fresno, CA, with PAM failed to show improved infiltration. Laboratory experiments were conducted to investigate PAM effect on infiltration of various quality waters in sandy loam soils. Two formulations of a high molecular weight PAM, a liquid emulsion and a granular, were evaluated on a Hanford sandy loam soil (coarse-loamy, mixed, superactive, nonacid, thermic Typic Xerorthents) in packed soil column experiments. Applying PAM continuously in the infiltration water always decreased infiltration for all PAM concentrations tested (5-20 mg PAM $\mathrm{L}^{-1}$ ). Final infiltration rates of $5 \mathrm{mg} \mathrm{PAM} \mathrm{L}^{-1}$ relative to infiltration rate of deionized water were $65 \%$ for emulsion PAM and $36 \%$ for granular PAM and these ratios decreased with increasing PAM concentration. Reduction of infiltration rates when PAM was applied with water containing $\mathrm{Ca}$ (applied as gypsum) was less than with PAM solution containing Na. Permeability tests of PAM solutions through uniform sands showed a decrease of permeability with increased concentrations, due to an apparent increase in effective viscosity of the solution. The decrease in infiltration rates in this study was likely due to this increase in viscosity when PAM is added to water. This research concluded that PAM applied in irrigation water will reduce infiltration unless the material improves surface soil aggregate structure and sustains pores sufficient to mask the effect of solution viscosity.
\end{abstract}

$\mathrm{S}_{\mathrm{s}}^{\mathrm{L}}$ OW INFILTRATION rates can make irrigation more difficult and expensive (Trout et al., 1990). Slow infiltration rates on sloping surface-irrigated fields can result in high runoff, requiring longer irrigation durations and greater frequency of irrigation to meet irrigation demands. Slow infiltration on level surface-irrigated fields can result in crop damage due to standing water or inadequate aeration in the root zone, and can even result in algae growth on the soil surface that further slows infiltration. Infiltration rates slower than sprinkler or drip emitter application rates result in water ponding and reduced application uniformity. Water standing on the soil surface can increase evaporation losses. Wet surface soil increases weed growth, changes the weed species mix, and delays access to the field.

Slow infiltration is commonly associated with finetextured soils. However, slow infiltration can develop in sandy loam soils with low organic matter content and is a major problem for crop production in some areas of California's San Joaquin Valley (Singer and Oster,

H.A. Ajwa, Univ. of California-Davis, 1636 E. Alisal St., Salinas, CA 93905; T.J. Trout, USDA-ARS, 9611 S. Riverbend Ave., Parlier, CA 93648. Received 15 Mar. 2005. *Corresponding author (haajwa@ ucdavis.edu).

Published in Soil Sci. Soc. Am. J. 70:643-650 (2006).

Soil \& Water Management \& Conservation

doi:10.2136/sssaj2005.0079

(c) Soil Science Society of America

677 S. Segoe Rd., Madison, WI 53711 USA
1984). Slow infiltration in medium and coarse-textured soils in California can be caused by restrictive layers at the surface such as crusts or seals, or below the surface such as compacted layers, pans, lenses, fine-textured strata, or cemented layers (Oster et al., 1992). It can also result from dispersion of the fine particles due to sodicity, or lack of sufficient divalent cations such as calcium, or from swelling of smectite clays with wetting.

Various types of PAM have been used for over $50 \mathrm{yr}$ to improve soil structure and permeability. Experiments conducted with high molecular weight PAMs at low concentrations in furrow irrigation water have been very successful in reducing irrigation-induced erosion (Lentz et al., 1992; Lentz and Sojka, 1994; Sojka et al., 1998a, 1998b). Several studies have noted increased infiltration rates when PAM is added to furrow irrigation water (Trout et al., 1995; Sojka et al., 1998a, 1998b), to sprinkler irrigation water (Levy et al., 1991; Bjorneberg and Aase, 2000; Bjorneberg et al., 2003), or sprayed on the soil surface (Flanagan et al., 1997; Green et al., 2000; Zhang and Miller, 1996). McElhiney and Osterli (1996) showed that PAM, applied to a fine-textured soil in the San Joaquin Valley, resulted in a 10 to $40 \%$ increase in infiltration rate. Because erosion is reduced and aggregates are more stable with PAM, deposition of low permeability surface layers is reduced. When PAM is used, the more porous structure of the surface soil is often visible. Although PAM does not increase soil permeability, it reduces the decline in permeability due to aggregate breakdown and seal formation (McElhiney and Osterli, 1996).

Most of the PAM studies have been performed on clay loam or silt loam soils with low aggregate stability and on moderate to steep slopes where soil erosion is evident. The sandy loam soils in the San Joaquin Valley are generally on level or very low slopes and erosion is not evident, although surface seal formation has been proposed as a reason for low infiltration. Trout and Ajwa (2001) performed a series of field tests near Fresno, CA, on Hanford sandy loam soils to determine whether emulsion PAM addition to furrow irrigation water resulted in increased infiltration rates. Two series of field-scale trials in a furrow-irrigated vineyard and two series of recirculating infiltrometer trials in a fallow field using water of three ion concentrations $(\mathrm{EC}=0.03,0.3$, and $1.2 \mathrm{dS} \mathrm{m}^{-1}$ ) failed to show any increase in infiltration with PAM. In fact, the results from several trials (15 of 18 comparisons) indicated that PAM addition to irrigation water slightly decreased infiltration. Although the effect of PAM on the structure of the furrow perimeter was sometimes visible, very little erosion or

Abbreviations: DI, deionized; EC, electrical conductivity; PAM, polyacryamide; RFI, relative flocculation index; SAR, sodium adsorption ratio. 
sediment movement was evident with low water flow velocities in the nearly level furrows.

Although the chemical composition of water can affect infiltration rates and hydraulic conductivity of soils, limited information is available on the interaction between PAM and salts in irrigation water on infiltration rate. Water quality may interact with the chemical structure of PAM (Shainberg et al., 1990; Wallace and Wallace, 1996) and can change its behavior in soil. Shainberg et al. (1990) found that salts in soil solution that flocculate the clay minerals enhanced the beneficial effect of polymers on aggregate stability. El-Morsy et al. (1991a, 1991b) investigated the combined effects of polymers and salts in water (EC values of $0.5,2$, and $5 \mathrm{dS} \mathrm{m}^{-1}$ and SAR values of 5,15 , and 25 ) on soil hydraulic conductivity and found that the beneficial effects of the polymer were greater in soils treated with water that has high EC values. In addition to salts in irrigation water, high PAM concentration and surfactants may affect infiltration. Recently, Lentz (2003) found that applying $10 \mathrm{mg}$ PAM $\mathrm{L}^{-1}$ plus anionic surfactant to silt loam and sandy loam soils reduced saturated hydraulic conductivity by up to $70 \%$ relative to the same PAM concentration without surfactant.

The timing of application and formulation of PAM may also affect water infiltration. Several PAM application sequences have been followed: (1) continuous application throughout the irrigation period; (2) application during the advance time in furrow irrigation or at the beginning of the irrigation in sprinkler application; (3) initial followed by intermittent application; and (4) application of concentrated PAM solutions to the soil surface before initiation of irrigation. Although several studies evaluated optimum PAM application practices for medium-to-heavy-textured soils (Trout et al., 1995; Sojka et al., 1998a, 1998b; Lentz and Sojka, 2000a, 2000b; Lentz et al., 2002; Bjorneberg et al., 2003), limited information is available on application practices for use of high molecular weight PAM with various quality water in furrow irrigated sandy loam soils that exhibit slow infiltration rates.

The objectives of this research were to: (1) determine the impact of PAM on infiltration into sandy loam soils prevalent in the San Joaquin Valley; and (2) investigate the interaction between PAM and salt type and concentration in water on the solution viscosity, soil flocculation, and water infiltration rate.

\section{MATERIALS AND METHODS}

Two high molecular weight (12-15 Da) negatively charged PAM formulations (Pristine and Superfloc) were used in this study. Pristine (American Cyanamid Co., Wayne, NJ) is a $30 \%$ a.i. liquid emulsion (acrylamide/acrylic acid and ammonium salt plus $26 \%$ oil emulsion and $44 \%$ water) with high charge density (35\% hydrolysis). The liquid emulsion contains a small percentage of surfactants and salts to help maintain and invert the emulsion state during storage and preparation for use. Superfloc A-110 (previously named Magnifloc 836A, CYTEC Industries Inc., West Paterson, $\mathrm{NJ}$ ) is $80 \%$ a.i. granular crystals and $10 \%$ urea with medium charge density (18\% hydrolysis). All PAM solutions were completely dissolved by mixing for $1 \mathrm{~h}$ by magnetic stirrer. All PAM concentrations are reported on an active ingredient basis.

\section{Water Viscosity Experiments}

Polyacrylamide is a nonNewtonian fluid whose viscosity is not constant and viscometers cannot measure the viscosity impacts of low PAM concentrations $\left(<100 \mathrm{mg} \mathrm{PAM} \mathrm{L}^{-1}\right.$, active ingredient). Therefore, the relative solution viscosity $(\eta)$ of the two PAM formulations was determined in a constant head permeameter following procedures described by Malik and Letey (1992). In brief, uniform size silica sand (standard Ottawa sand, 30-40 mesh) was packed in glass columns and saturated from below by immersion into the solution. Solution flow through the column of varying PAM concentrations in deionized (DI) water was measured under a constant $20-\mathrm{mm}$ head. Also, 10 and $20 \mathrm{mg}$ PAM L ${ }^{-1}$ solutions were prepared with $\mathrm{CaSO}_{4} \cdot 2 \mathrm{H}_{2} \mathrm{O}$ to have EC values of $0.3 \mathrm{dS} \mathrm{m}{ }^{-1}\left(\mathrm{EC}_{0.3}\right)$ and $1.5 \mathrm{dS} \mathrm{m}^{-1}\left(\mathrm{EC}_{1.5}\right)$, or prepared with $\mathrm{NaCl}$ plus $\mathrm{CaCl}_{2}$ salts to have SAR values of $9\left(\mathrm{SAR}_{9}\right.$, with an $\mathrm{EC}$ value of $\left.0.5 \mathrm{dS} \mathrm{m}^{-1}\right)$ and $18\left(\mathrm{SAR}_{18}\right.$, with an EC value of $\left.1.0 \mathrm{dS} \mathrm{m}{ }^{-1}\right)$. The steadystate flow rate through the column was measured and the hydraulic conductivity was calculated for the various PAM concentrations and water qualities. The relative fluid viscosity was calculated, based on the Kozeny-Carman equation (Corey, 1977), from relative hydraulic conductivities $\left(K_{\mathrm{PAM}}\right)$ and densities $\left(\rho_{\mathrm{PAM}}\right)$ of PAM (or PAM plus salt), and that of solutions containing no PAM as follows:

$$
\eta=\eta_{\mathrm{PAM}} / \eta_{\mathrm{w}}=\rho_{\mathrm{PAM}} K_{\mathrm{w}} / \rho_{\mathrm{w}} K_{\mathrm{PAM}}
$$

\section{Soil Flocculation Experiments}

Procedures similar to those described by Laird (1997) were followed to investigate the effect of interaction between PAM and various qualities of water on soil flocculation. A soil sample (Hanford sandy loam) was shaken in $10 \mathrm{mg}$ PAM L ${ }^{-1}$ prepared in DI water or various quality water to achieve a homogeneous suspension. A portion was poured into a cuvet and placed into a spectrophotometer. Absorbance at $500 \mathrm{~nm}$ was measured after 5 min. Relative Flocculation Index (RFI) was calculated as absorbance for soil prepared with PAM (or PAM plus salt) to absorbance for soil prepared with only DI water or with salt solutions without PAM. All viscosity and flocculation results were determined from at least five replicates.

\section{Column Infiltration Studies}

Surface $(0-15 \mathrm{~cm})$ Hanford sandy loam soil (coarse-loamy, mixed, thermic Typic Durizeralf), a typical soil in the San Joaquin Valley, was collected from a 25 -yr-old vineyard in Parlier, CA. The soil contained $62 \%$ sand, $11 \%$ clay, $0.6 \%$ organic $\mathrm{C}$, had 0.7 to $1.0 \mathrm{dS} \mathrm{m}^{-1}$ electrical conductivity, and had a pH value of 6.8 and soil-water (1:1 ratio) extractable $\mathrm{Ca}, \mathrm{Na}$, and $\mathrm{Mg}$ concentrations of $4,3.0$, and $2.1 \mathrm{mmol}_{\mathrm{c}} \mathrm{L}^{-1}$, respectively. The cation exchange capacity and SAR values of the soil were $10.1 \mathrm{cmol}_{\mathrm{c}} \mathrm{kg}^{-1}$ and 1.7 , respectively. The soil was air dried, passed through a 4-mm sieve, and packed into PVC columns (25-cm diam. and $56 \mathrm{~cm}$ long) to mimic a typical field soil bulk density of $1.55 \mathrm{Mg} \mathrm{m}^{-3}$. Three application sequences of 5,10, and $20 \mathrm{mg} \mathrm{PAM} \mathrm{L}^{-1}$ prepared with DI water or $10 \mathrm{mg}$ PAM L ${ }^{-1}$ prepared with various water qualities $\left(\mathrm{EC}_{0.3}, \mathrm{EC}_{1.5}\right.$, $\mathrm{SAR}_{9}$, and $\mathrm{SAR}_{18}$ ) were evaluated: (i) constant PAM concentration in water throughout the irrigation period (continuous); (ii) pre-irrigation application of PAM in $20 \mathrm{~mm}$ of water and followed immediately with DI water ( $20 \mathrm{~mm}$, no delay); and (iii) pre-irrigation application of PAM in $20 \mathrm{~mm}$ of water, 
allowed the soil to dry for $48 \mathrm{~h}$, and then continued the irrigation with DI water ( $20 \mathrm{~mm}, 48 \mathrm{~h}$ delay). In all cases, as water ponded on the soil surface, the column was rocked gently for a few seconds to create water movement on the surface to mimic overland flow conditions typical of surface irrigation.

The infiltration water was applied via Mariotte siphon to maintain a constant head $(20 \mathrm{~mm})$ above the soil surface. Each infiltration test was run for $400 \mathrm{~min}$. Pressure transducers and dataloggers were used to monitor the rate of water discharge from the burettes. Final infiltration rate was determined when the infiltration reached a steady-state condition (between 240 and $400 \mathrm{~min}$.). Cumulative infiltration, $I(\mathrm{~mm})$, during the early stages of the tests was used to calculate sorptivity coefficients $(S)$ using the following equation (Philip, 1957):

$$
I=S t^{1 / 2}
$$

where $t$ is the infiltration time (min.). Sorptivity was estimated from the slope of the measured $I$ vs. $t^{1 / 2}$ relationship.

\section{Statistical Analysis}

Three replicates of all column infiltration experiments were conducted over time. Each replicate consisted of six or eight treatments. The infiltration columns and silica tubes were arranged in a complete randomized design. General linear model (GLM) tests were performed using the Statistical Analysis System (SAS) program (SAS Institute, 2000) to compare the two PAM formulations and to determine the effect of PAM with various EC and SAR values on final infiltration rates and sorptivity coefficients of soil. When significant $(P<0.05)$ treatment differences were found, Fisher's protected LSD values were calculated to separate the treatment means. The GLM and Fisher's LSD tests were also performed to determine the effect of PAM and various qualities of water on $\eta$ and RFI values for the two PAM formulations.

\section{RESULTS}

\section{Water Viscosity and Soil Flocculation Experiments}

Relative viscosity measurements, conducted using silica sand in the constant head permeameters, showed that the apparent viscosity of dilute PAM solutions increases linearly with increasing PAM concentration (Fig. 1), and that this increase depends on PAM formulation and the

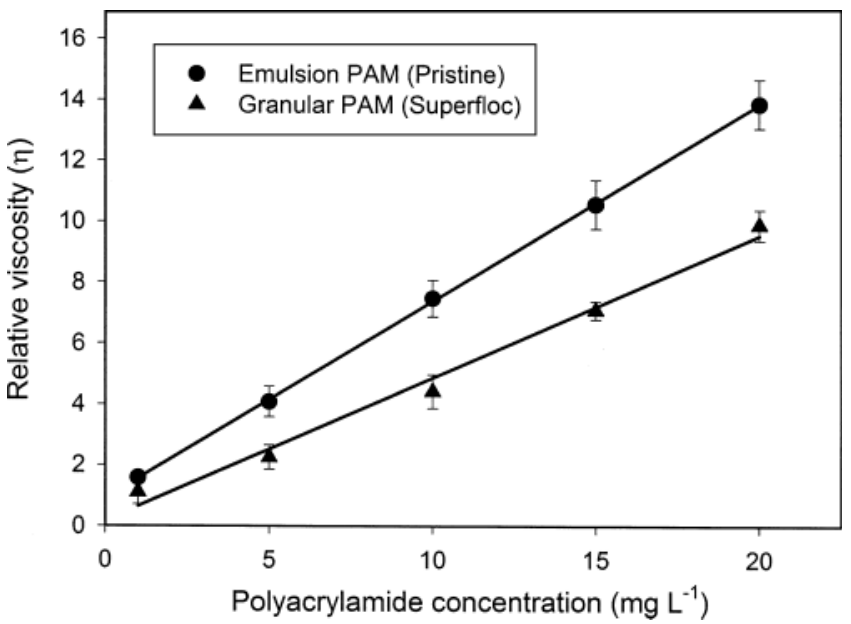

Fig. 1. Relative viscosity $(\eta)$ of polyacrylamide solutions prepared in deionized water determined in silica sand. Error bars indicate standard deviation.
Table 1. Relative viscosity $(\eta)$ of polyacrylamide solutions prepared in water with various electrical conductivity (EC) and sodium absorption ratio (SAR) values relative to viscosity of the same salt solutions without polyacrylamide (PAM).

PAM concentration $\left(\mathrm{mg} \mathrm{L}^{-1}\right)$ and
water quality

$\eta$ for two formulations of PAM

10 mg PAM $\mathrm{L}^{-1}$ prepared in

deionized (DI) water

$10 \mathrm{mg}$ PAM $\mathrm{L}^{-1}$ prepared in $\mathrm{EC}_{03}$

$10 \mathrm{mg}$ PAM $\mathrm{L}^{-1}$ prepared in $\mathrm{EC}_{1}$

$10 \mathrm{mg} \mathrm{PAM} \mathrm{L}^{-1}$ prepared in $\mathrm{SAR}_{9}$ :

$10 \mathrm{mg}$ PAM $\mathrm{L}^{-1}$ prepared in $\mathrm{SAR}_{18}$

LSD 0.05

$20 \mathrm{mg}$ PAM $\mathrm{L}^{-1}$ prepared in DI water

$20 \mathrm{mg}$ PAM $\mathrm{L}^{-1}$ prepared in $\mathrm{EC}_{0.3}$

$20 \mathrm{mg}$ PAM $\mathrm{L}^{-1}$ prepared in $\mathrm{EC}_{1.5}$

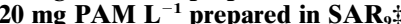

$20 \mathrm{mg}$ PAM $\mathrm{L}^{-1}$ prepared in $\mathrm{SAR}_{18}$

LSD 0.05

Emulsion PAM Granular PAM

$7.48(0.60) \mathrm{a} \quad 4.42(0.20) \mathrm{b}$

$3.16(0.11) a \quad 0.94(0.07) b$

$3.21(0.19) \mathrm{a} \quad 1.02(0.06) b$

$4.42(0.19) \mathrm{a} \quad 1.41(0.09) \mathrm{b}$

$4.25(0.27) a \quad 1.39(0.11) b$

1.17

$9.89(0.46) b$

$\begin{array}{ll}13.87(0.78) \mathrm{a} & 9.89(0.46) \mathrm{b} \\ 3.65(0.24) \mathrm{a} & 1.64(0.05) \mathrm{b}\end{array}$

$3.70(0.16) a-1.67(0.04) b$

$4.01(0.11) \mathrm{a} \quad 1.92(0.13) \mathrm{b}$

$4.17(0.10) \mathrm{a} \quad 1.82(0.05) \mathrm{b}$

$\begin{array}{lll}1.37 & 0.79\end{array}$

$\dagger$ Standard deviation values are in parentheses. Numbers followed by the same letter in each row are not significantly different at $P<0.05$.

$\$$ The EC values of $S A R_{9}$ and $S A R_{18}$ solutions were 0.5 and $1.0 \mathrm{dS} \mathrm{m}^{-1}$.

type and amount of salt present in water (Table 1). Increasing PAM concentration from 1 to $20 \mathrm{mg} \mathrm{PAM} \mathrm{L}^{-1}$ in DI water increased relative viscosity by more than $800 \%$, and the rate of this increase was $40 \%$ greater in emulsion PAM than in granular PAM. The relationship between relative viscosity and PAM concentration was linear $\left(R^{2}=0.99\right)$ for each PAM formulation:

$$
\begin{gathered}
\text { Emulsion PAM (Pristine) }: \eta_{\mathrm{p}}=0.65 \\
\quad \times(\text { PAM concentration })+0.91,
\end{gathered}
$$

and

$$
\begin{array}{r}
\text { Granular PAM (Superfloc) }: \eta_{\mathrm{s}}=0.47 \\
\times(\text { PAM concentration })+0.18 .
\end{array}
$$

Addition of $\mathrm{Ca}$ or $\mathrm{Na}$ ions to the water greatly reduced the effect of PAM on the relative viscosity. However, Ca and $\mathrm{Na}$ addition to water without PAM did not affect the relative viscosity (data not shown).

The effect of PAM prepared in DI water on soil flocculation is shown in Fig. 2. A high RFI indicates a

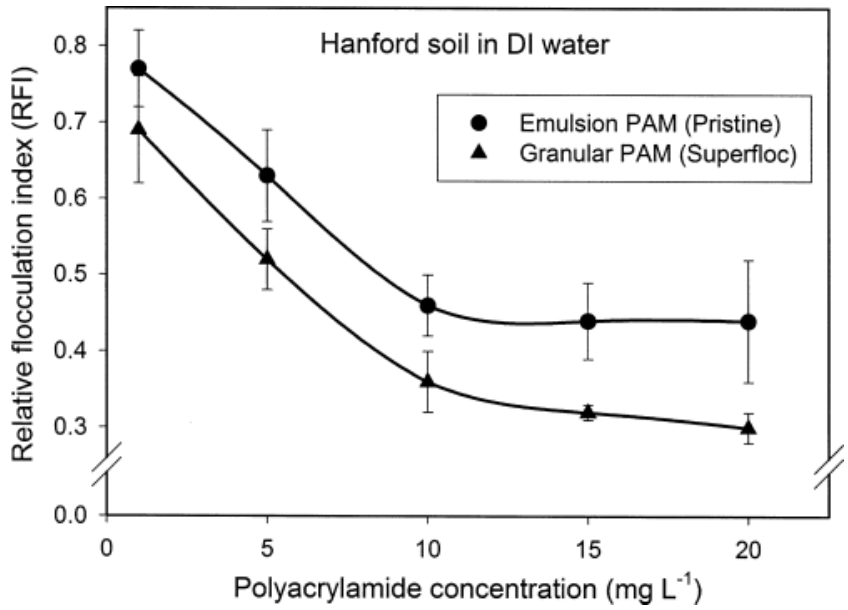

Fig. 2. Effect of polyacrylamide concentration on flocculation index for Hanford sandy loam soil. Polyacrylamide solution was prepared in deionized water. Error bars indicate standard deviation. 
Table 2. Effect of polyacrylamide (PAM) in water with various electrical conductivity (EC) and sodium absorption ratio (SAR) values on relative flocculation index (RFI $\dagger$ ) of Hanford sandy loam soil.

\begin{tabular}{|c|c|c|c|c|c|}
\hline \multirow[t]{2}{*}{ Water quality } & \multirow[t]{2}{*}{0 mg PAM $\mathbf{L}^{-1}$} & \multicolumn{2}{|c|}{$10 \mathrm{mg}$ PAM $\mathrm{L}^{-1}$} & \multicolumn{2}{|c|}{$20 \mathrm{mg}$ PAM $\mathrm{L}^{-1}$} \\
\hline & & Emulsion & Granular & Emulsion & Granular \\
\hline Deionized water & $1.00(0.10) a$ & $0.46(0.04) b$ & $0.36(0.04) b$ & $0.44(0.08) b$ & $0.30(0.02) b$ \\
\hline $\mathbf{E C}_{0.3}$ & $0.87(0.04) a$ & $0.05(0.01) b$ & $0.06(0.01) b$ & $0.08(0.01) b$ & $0.05(0.02) b$ \\
\hline $\mathbf{E C}_{1.5}$ & $0.07(0.06) a$ & $0.03(0.02) b$ & $0.03(0.02) b$ & $0.04(0.01) b$ & $0.03(0.03) b$ \\
\hline $\mathbf{S A R}_{\mathbf{9}} \div$ & $1.13(0.08) a$ & $0.31(0.07) c$ & $0.68(0.04) b$ & $0.31(0.06) c$ & $0.59(0.05) b$ \\
\hline $\mathbf{S A R}_{18} \ddagger$ & $0.91(0.09) a$ & $0.49(0.09) b c$ & 0.71 (0.06)ab & $0.38(0.05) c$ & $0.63(0.05) b c$ \\
\hline $\mathbf{L S D}_{0.05}$ & 0.28 & 0.20 & 0.14 & 0.18 & 0.13 \\
\hline
\end{tabular}

$\dagger$ RFI = $\mathbf{A}_{\text {PAM-Salt }} / \mathbf{A}_{\text {Salt }}$, where $\mathbf{A}_{\text {PAM-Salt }}$ is absorbance at $500 \mathrm{~nm}$ for soil prepared with PAM plus salt and $\mathbf{A}_{\text {Salt }}$ is absorbance for soil prepared only with salt. For solutions with no PAM, RFI $=\mathbf{A}_{\text {Salt }} / \mathbf{A}_{\mathrm{DI}}$. Standard deviation values are in parentheses. Numbers followed by the same letter in each row are not significantly different at $P<0.05$.

$\uparrow$ The EC values of $S A R_{9}$ and $S A R_{18}$ solutions were 0.5 and $1.0 \mathrm{dS} \mathrm{m}^{-1}$.

slight difference between water containing PAM and water without PAM, and a low value indicates that PAM application caused the soil to flocculate and settle out of suspension. For both PAM formulations, the degree of flocculation increased with concentrations between 1 and $10 \mathrm{mg}$ PAM L ${ }^{-1}$, and remained fairly constant at concentrations greater than $10 \mathrm{mg}$ PAM L ${ }^{-1}$. For all PAM concentrations, the emulsion PAM (Pristine) was less effective (had a greater RFI value) than the granular formulation.

Soil suspensions in PAM solutions with water containing $\mathrm{Ca}$ salt from gypsum $\left(\mathrm{EC}_{0.3}\right.$ and $\left.\mathrm{EC}_{1.5}\right)$ flocculated rapidly (Table 2). Soil suspension prepared with gypsum but without PAM had relatively large RFI values. There were no significant differences among RFI values for emulsion PAM prepared in DI water and the two $\mathrm{Na}$ concentrations. In the $\mathrm{Na}$ salt systems, granular PAM had greater RFI values than emulsion PAM.

\section{Column Infiltration Studies}

The effect of increasing PAM concentration applied continuously in the infiltrating water (continuous application) on cumulative infiltration in Hanford sandy loam soil is shown in Fig. 3. Similar cumulative infiltration curves were used to calculate the final infiltration rate and sorptivity coefficients for all PAM treatments and application sequences. Applying PAM continuously in the

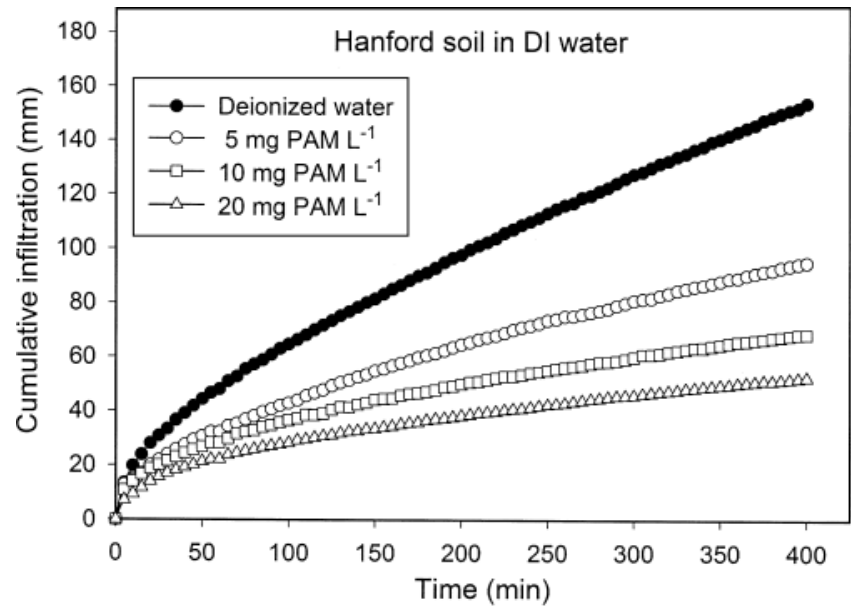

Fig. 3. Effect of emulsion polyacrylamide (Pristine) concentration prepared in deionized water on cumulative infiltration of water into Hanford sandy loam soil (continuous application). infiltrating water always decreased final infiltration rate (Table 3) and sorptivity coefficient (Table 4) for all PAM concentrations tested. Final infiltration rates of $5 \mathrm{mg}$ PAM $\mathrm{L}^{-1}$ relative to infiltration rate of DI water were $65 \%$ for emulsion PAM and $36 \%$ for granular PAM and these ratios decreased with increasing PAM concentration.

Application of PAM in only the initial $20 \mathrm{~mm}$ of water added to the column (20 mm, no delay) decreased sorptivity (early infiltration) similar to continuous application, but the decrease in final infiltration rate was less than for continuous application. For the lowest $(5 \mathrm{mg}$ PAM L ${ }^{-1}$ ) concentration tested, final infiltration rate increased relative to that of DI water. This indicates that the impact of the PAM on infiltration was primarily due to the concentration and viscosity effect in the infiltrating water, but there might be some residual effect from the previously infiltrated PAM solution. When PAM was applied in $20 \mathrm{~mm}$ water and the soil allowed to dry for $48 \mathrm{~h}$ before irrigation was resumed $(20 \mathrm{~mm}, 48$-h delay treatment), the infiltration reductions were small and not significantly different from those without PAM, except for sorptivity at the highest PAM concentration $(20 \mathrm{mg}$ $\mathrm{PAM} \mathrm{L}^{-1}$ ). These results indicate that any residual effect of the PAM molecules in the soil was small.

Results using $10 \mathrm{mg}$ PAM L ${ }^{-1}$ on two other soil types [Chualar loam (fine-loamy, mixed, superactive, thermic

Table 3. Effect of two formulations of polyacrylamide (PAM) on final infiltration rate of water in Hanford sandy loam soil under three application sequences.

\begin{tabular}{|c|c|c|c|}
\hline \multirow[t]{2}{*}{$\begin{array}{l}\text { PAM concentration } \\
\left(\mathrm{mg} \mathrm{L}^{-1}\right)\end{array}$} & \multicolumn{3}{|c|}{ Final infiltration rate $\left(\mathrm{mm} \mathrm{h}^{-1}\right) \dagger$} \\
\hline & Continuousł & $\begin{array}{l}20 \text { mm, } \\
\text { no delay§ }\end{array}$ & $20 \mathrm{~mm}$, \\
\hline $\begin{array}{l}\text { Deionized water } \\
\text { Emulsion PAM }\end{array}$ & $12.5(1.0) \mathrm{a}$ & $12.1(0.8) \mathrm{a}$ & $12.2(0.7) \mathrm{a}$ \\
\hline 5 & $8.1(0.6) b$ & $15.0(1.3) a b$ & $11.3(0.5) \mathrm{a}$ \\
\hline 10 & $5.9(0.5) c$ & $7.8(0.1) \mathrm{b}$ & $10.8(0.5) \mathbf{a}$ \\
\hline & $5.3(0.9) \mathrm{b}$ & $6.1(0.6) \mathrm{b}$ & $10.2(0.6) \mathrm{a}$ \\
\hline \multicolumn{4}{|l|}{ Granular PAM } \\
\hline 5 & $4.5(1.1) b$ & $14.3(1.3) a$ & $10.6(0.3) \mathrm{a}$ \\
\hline 10 & $3.3(0.8) \mathrm{b}$ & $11.3(0.9) a$ & $10.5(0.3) \mathrm{a}$ \\
\hline & $2.9(0.5) b$ & 8.4 (1.1)a & $10.5(0.5) \mathrm{a}$ \\
\hline $\mathbf{L S D}_{0.05}$ & 2.7 & 3.2 & 1.7 \\
\hline
\end{tabular}

$\dagger$ Standard deviation values are in parentheses. Numbers followed by the same letter in each row are not significantly different at $P<0.05$.

$\Varangle$ Constant PAM concentration in water throughout the irrigation period. $\$$ Pre-irrigation application of PAM in $20 \mathrm{~mm}$ water and followed immediately with DI water.

II Pre-irrigation application of PAM in $20 \mathrm{~mm}$ water, allowed the soil to dry for $48 \mathrm{~h}$, and then continued the irrigation with deionized water. 
Table 4. Effect of two formulations of polyacrylamide (PAM) on sorptivity coefficient of Hanford sandy loam soil under three application sequences.
PAM concentration

(mg L $\left.\mathbf{~ L}^{-1}\right)$

Sorptivity coefficient $\left(\mathrm{mm} \mathrm{min}^{-1 / 2}\right) \dagger$

Continuous
$6.6(0.7) a$

$4.2(0.3) b$
$3.6(0.2) a$
$2.8(0.2) a$

$3.6(0.4) b$
$2.9(0.7) b$
$2.0(0.2) b$
1.5

\begin{tabular}{cc}
$\begin{array}{c}20 \mathrm{~mm}, \\
\text { no delay } \S\end{array}$ & $\begin{array}{c}20 \mathrm{~mm}, \\
\mathbf{4 8}-\mathrm{h} \text { delay }\end{array}$ \\
$6.7(0.8) \mathrm{a}$ & $6.4(0.8) \mathrm{a}$ \\
& \\
$5.0(0.3) \mathrm{ab}$ & $6.0(0.3) \mathrm{a}$ \\
$2.8(0.2) \mathrm{b}$ & $3.8(0.3) \mathrm{a}$ \\
$2.4(0.3) \mathrm{a}$ & $3.3(0.3) \mathrm{a}$ \\
& \\
$5.5(0.2) \mathrm{a}$ & $5.9(0.2) \mathrm{a}$ \\
$4.1(0.1) \mathrm{ab}$ & $5.7(0.3) \mathrm{a}$ \\
$3.1(0.4) \mathrm{b}$ & $5.2(0.3) \mathrm{a}$ \\
1.3 & 1.3 \\
\hline
\end{tabular}

Standard deviation values are in parentheses. Numbers followed by the same letter in each row are not significantly different at $\boldsymbol{P}<0.05$.

$¥$ Constant PAM concentration in water throughout the irrigation period.

$\$$ Pre-irrigation application of PAM in $20 \mathrm{~mm}$ water and followed immediately with DI water.

II Pre-irrigation application of PAM in $20 \mathrm{~mm}$ water, allowed the soil to dry for $48 \mathrm{~h}$, and then continued the irrigation with deionized water.

Typic Argixerolls) and Wasco sandy clay loam (coarseloamy, mixed, superactive, nonacid, thermic Typic Torriorthents] in column studies were similar to results reported above for Hanford sandy loam soil (data not shown). However, the decrease in final infiltration rates and sorptivity coefficients caused by PAM application to Chualar and Wasco soils were 10 to $20 \%$ less than those found in Hanford soil.

The effects of the interaction between $10 \mathrm{mg} \mathrm{PAM} \mathrm{L}^{-1}$ (applied as emulsion PAM) and various water qualities on the final infiltration rates and sorptivity coefficients are shown in Tables 5 and 6 , respectively. Continuously applying water containing $\mathrm{Ca}\left(\mathrm{EC}_{0.3}\right.$ or $\left.\mathrm{EC}_{1.5}\right)$ or $\mathrm{Na}$ $\left(\mathrm{SAR}_{9}\right.$ or $\left.\mathrm{SAR}_{18}\right)$ without PAM generally increased infiltration compared with DI water. Although the increase in infiltration rate was not statistically different $(P<0.05)$ among water treatments without PAM, continuous application of PAM in water containing $\mathrm{Na}$ salt

Table 5. Effect of emulsion polyacrylamide $\left(10 \mathrm{mg}\right.$ PAM $\left.\mathrm{L}^{-1}\right)$ and various quality water on final infiltration rate in Hanford sandy loam soil under three application sequences.

\begin{tabular}{|c|c|c|c|}
\hline \multirow{2}{*}{ Infiltration water } & \multicolumn{3}{|c|}{ Final infiltration rate $\left(\mathrm{mm} \mathrm{h}^{-1}\right) \dagger$} \\
\hline & Continuousł & $\begin{array}{l}20 \mathrm{~mm} \text {, } \\
\text { no delay } \$\end{array}$ & $\begin{array}{l}20 \mathrm{~mm}, \\
48 \mathrm{~h} \text { delay }\end{array}$ \\
\hline Deionized (DI) water & $12.5(1.0) \mathrm{a}$ & $12.1(0.8) a$ & $12.2(1.0) \mathrm{a}$ \\
\hline DI water + PAM & $6.9(1.2) b$ & $7.6(0.7) b$ & $11.3(0.4) a$ \\
\hline $\mathbf{E C}_{0.3}$ Water & $15.4(0.7) \mathrm{a}$ & $15.5(0.6) \mathrm{a}$ & $12.4(0.6) b$ \\
\hline $\mathbf{E C}_{0.3}+\mathbf{P A M}$ & $11.6(1.0) a$ & 8.4 (1.1)a & $12.0(0.3) \mathrm{a}$ \\
\hline EC $_{1.5}$ Water & 15.4 (1.2)a & $15.3(0.2) \mathrm{a}$ & $13.4(0.2) \mathrm{a}$ \\
\hline $\mathbf{E C}_{1.5}+\mathbf{P A M}$ & 13.1 (1.1)a & 11.1 (1.4)a & $12.1(0.3) a$ \\
\hline SAR, Water & 13.2 (1.1)a & $12.0(0.5) \mathrm{a}$ & $11.7(0.4) a$ \\
\hline $\mathbf{S A R}_{9}+\mathbf{P A M}$ & $8.6(0.7) b$ & $7.2(0.6) \mathrm{b}$ & $11.8(0.8) a$ \\
\hline $\mathbf{S A R}_{18}$ Water & 15.0 (1.0)a & $13.0(0.5) \mathrm{a}$ & $12.0(0.4) \mathrm{a}$ \\
\hline $\mathbf{S A R}_{18}+\mathbf{P A M}$ & $7.9(0.6) b$ & $6.4(0.4) \mathrm{b}$ & $11.3(0.7) a$ \\
\hline $\mathbf{L S D}_{0.05}$ & 3.1 & 2.4 & 1.8 \\
\hline
\end{tabular}

$\dagger$ Standard deviation values are in parentheses. Numbers followed by the same letter in each row are not significantly different at $\boldsymbol{P}<0.05$.

$\ddagger$ Constant PAM concentration in various quality water throughout the irrigation period.

$\S$ Pre-irrigation application of PAM in $20 \mathrm{~mm}$ of various quality water and followed immediately with DI water.

If Pre-irrigation application of PAM in $20 \mathrm{~mm}$ of various quality water, allowed the soil to dry for $48 \mathrm{~h}$, and then continued the irrigation with DI water.
Table 6. Effect of emulsion polyacrylamide $\left(10 \mathrm{mg}\right.$ PAM $\left.\mathrm{L}^{-1}\right)$ and various quality water on sorptivity coefficient of Hanford sandy loam soil under three application sequences.

\begin{tabular}{|c|c|c|c|}
\hline \multirow[t]{2}{*}{ Infiltration water $\dagger$} & \multicolumn{3}{|c|}{ Sorptivity coefficient $\left(\mathrm{mm} \min ^{-1 / 2}\right) \uparrow$} \\
\hline & Continuous§ & $\begin{array}{l}20 \mathrm{~mm} \text {, } \\
\text { no delayII }\end{array}$ & $\begin{array}{l}20 \mathrm{~mm}, \\
48 \mathrm{~h} \text { delay\# }\end{array}$ \\
\hline DI water & $6.6(0.7)$ & $6.7(0.8)$ & $6.7(0.5)$ \\
\hline DI water + PAM & $3.6(0.8)$ & $2.8(0.5)$ & $3.8(0.5)$ \\
\hline $\mathbf{E C}_{0.3}$ & $7.3(0.2)$ & $6.9(0.7)$ & $6.9(0.6)$ \\
\hline $\mathbf{E C}_{0.3}^{0.3}+\mathbf{P A M}$ & $4.2(0.3)$ & $3.3(0.4)$ & $4.8(0.3)$ \\
\hline $\mathbf{E C}_{1.5}$ & $7.8(0.3)$ & $7.2(0.3)$ & $7.1(0.4)$ \\
\hline $\mathbf{E C}_{1.5}+\mathbf{P A M}$ & $6.9(1.0)$ & $5.0(0.8)$ & $5.8(0.5)$ \\
\hline SAR, & $7.2(0.4)$ & $6.5(0.3)$ & $5.7(0.4)$ \\
\hline $\mathbf{S A R}_{9}+\mathbf{P A M}$ & $4.4(0.7)$ & $3.0(0.3)$ & $3.8(0.5)$ \\
\hline $\mathbf{S A R}_{18}$ & $6.9(0.5)$ & $7.0(0.4)$ & $5.3(0.8)$ \\
\hline $\mathbf{S A R}_{18}+\mathbf{P A M}$ & $3.5(0.3)$ & $2.8(0.4)$ & $3.6(0.5)$ \\
\hline $\mathbf{L S D}_{0.05}$ & 1.8 & 1.7 & 1.6 \\
\hline
\end{tabular}

$\dagger$ DI, deionized water; EC, electrical conductivity; SAR, sodium adsorption ratio.

$\ddagger$ Standard deviation values are in parentheses. Sorptivity coefficients were not significantly different $(P<0.05)$ among the three application sequences for each water treatment.

$\$$ Constant PAM concentration in various quality water throughout the irrigation period.

II Pre-irrigation application of PAM in $20 \mathrm{~mm}$ of various quality water and followed immediately with DI water.

\# Pre-irrigation application of PAM in $20 \mathrm{~mm}$ of various quality water, allowed the soil to dry for $48 \mathrm{~h}$, and then continued the irrigation with DI water.

significantly reduced infiltration by $35 \%\left(\mathrm{SAR}_{9}\right)$ and $47 \%\left(\mathrm{SAR}_{18}\right)$ relative to the same water without PAM. This reduction was similar to that created by PAM in DI water. Reduction in infiltration rates when PAM was applied with water containing Ca salt was less than with DI water or water containing Na. Calcium reduced the effect of PAM on infiltration.

The addition of emulsion PAM to the various quality waters and followed immediately with DI water $(20 \mathrm{~mm}$, no delay) reduced final infiltration rates and sorptivity coefficients in all cases. Water quality during preirrigation did not affect the PAM-induced infiltration reduction. When infiltration continued with the same water composition as the pre-irrigation water (data not shown), reduction in the infiltration rates compared with DI water varied from 16 to $28 \%$, substantially less than when infiltration continued with DI water $(20 \mathrm{~mm}$, no delay treatment). When the soil was allowed to dry for $48 \mathrm{~h}(20 \mathrm{~mm}, 48$-h delay treatment), final infiltration rates did not vary among the treatments. Water quality during the pre-irrigation did not impact the PAM effect on infiltration when the soil was allowed to dry before resuming irrigation with DI water. Except for the $\mathrm{EC}_{1.5}$ treatment, the sorptivity coefficients were significantly reduced with PAM application for the water quality treatments (Table 6). However, there were no significant differences among the application sequences for any of the water treatments.

\section{DISCUSSION}

The flow of fluids in porous media depends on properties of the media (soil) and fluid (water). Hydraulic conductivity, and thus flow rate, is inversely proportional to fluid viscosity (Corey, 1977). The relative viscosity tests showed that the flow of PAM solutions through clean, uniform silica sand was strongly affected by PAM 
concentration. These results predict a substantial reduction in soil infiltration with PAM, although the relative impact on infiltration will be less than the effect on hydraulic conductivity, due to the complex relationships among conductivity, soil water content, and matric potential. If the impact of PAM on the conductivity is related to a mechanical resistance to flow of the very large PAM molecules, then it is reasonable to assume that soil pore sizes and interactions between the PAM molecules and soil surfaces (soil and PAM ionic charge) will also impact the effect of PAM on hydraulic conductivity. In soils that form aggregates, however, it is difficult to separate the effects of PAM on soil properties (pore size and continuity) from the fluid properties (apparent viscosity). Flow in finer-textured soils (compared with silica sand) could be more impacted by PAM because of smaller and more tortuous flow paths and the attraction of the PAM to soil surfaces, or could be less impacted if the PAM molecules are quickly attached to soil particle surfaces and removed from the flow paths.

Ben-Hur and Keren (1997) reported that high viscosity decreases the solution flow rate in the soil pores allowing PAM molecules to interact with soil particles, which decreases infiltration rates. Other studies reported that low molecular weight PAM increased water infiltration more than high molecular weight, possibly due to greater viscosity of the high molecular weight PAM (Lentz and Sojka, 2000b). More recently, Lentz (2003) conducted column experiments using granular PAM (Superfloc) on silt loam soil and found that applying $125 \mathrm{mg}$ PAM L ${ }^{-1}$ decreased saturated hydraulic conductivity by $25 \%$, possibly due to increased apparent viscosity of water. This study supports earlier findings by Malik and Letey (1992), who showed that PAM at high concentrations $\left(>100 \mathrm{mg} \mathrm{L}^{-1}\right)$ could reduce water infiltration in coarse-textured soils, mainly by increasing the viscosity of the infiltrating water.

In our studies, the smaller infiltration reduction of the emulsion PAM formulations compared with granular PAM formulation was possibly due to the greater charge density (emulsion PAM has twice the charge density of granular PAM) and/or the presence of surfactants in the emulsion PAM formulation. Studies by Lentz and Sojka (2000a) compared 18 and $100 \%$ charge density, high molecular weight, anionic granular PAMs on repeat irrigated furrows, whose soil structure had been destroyed by previous irrigations. The $100 \%$ charged PAM increased infiltration in these repeat-irrigated furrows, whereas the $18 \%$ charged PAM reduced infiltration, relative to control furrows. This supports the concept that charge density, and not the presence of oil, additional salt, or surfactants/emulsifiers in the emulsion, was the key factor involved in the smaller infiltration reduction observed in our study. Also, the effect of increased apparent viscosity on infiltration may have been counteracted by the presence of hydrophobic groups (petroleum distillates) in the oil emulsion that reduced PAM adsorption to soil particles, and therefore, increased solution penetration in the soil (Lentz, 2003).

The chemical composition of water can affect the ability of PAM to flocculate soil particles. Shainberg et al. (1990) reported that electrolytes in the soil that flocculate the soil clay enhance the beneficial effect of the polymer on aggregate stability. Laird (1997) found that the efficacy of anionic PAM for clay flocculation was much greater with $\mathrm{Ca}$ than with $\mathrm{Na}$ in solution. Our results found that $3 \mathrm{mmol}_{\mathrm{c}} \mathrm{Ca} \mathrm{L}^{-1}\left(\mathrm{EC}_{0.3}\right)$ greatly improved the effectiveness of PAM to flocculate suspended sediments, likely due to the bridging effect of $\mathrm{Ca}$ between PAM and negatively charged soil particles. $\mathrm{Lu}$ et al. (2002) reported that application of $\mathrm{Ca}$ into irrigation water is necessary to ensure the effectiveness of PAM treatment because the application of divalent cations shrinks the electrical double layer and bridges the soil and PAM negative charge sites. In our study, water containing $\mathrm{Na}$ salt $\left(\mathrm{SAR}_{9}\right.$ and $\left.\mathrm{SAR}_{18}\right)$ and emulsion PAM did not affect soil flocculation differently than emulsion PAM in DI water. The Na salt with granular PAM, however, decreased soil flocculation relative to PAM in DI water (as indicated by increased RFI value). This decrease could have been caused by $\mathrm{Na}$ charge neutralization in the low charge density formulation (granular PAM), which reduced the ability of this formulation to aggregate soil particles.

The decrease in sorptivity coefficients and final infiltration rates measured in the infiltration columns with increasing PAM concentration was likely due to the increased apparent viscosity of the solutions. Even though the columns were gently rocked during initial filling to induce some surface flow and sediment movement, the effect of PAM on preserving aggregate structure and reducing sediment deposition and thus maintaining pore structure at the surface of this sandy loam soil was not adequate to compensate for the viscosity effect. A relative viscosity of 4 with granular PAM at $10 \mathrm{mg} \mathrm{L}^{-1}$ produced a final infiltration rate decline of $75 \%$, while a relative viscosity of 8 with the same concentration of emulsion PAM reduced infiltration by only $50 \%$, indicating a formulation-specific effect beyond that measured in the permeameter. While viscosity (and thus permeability) varied linearly with PAM concentration, infiltration declined by at least $35 \%$ from 0 to $5 \mathrm{mg}$ PAM $\mathrm{L}^{-1}$, and only by an additional $25 \%$ over a four-fold concentration increase from 5 to $20 \mathrm{mg}$ PAM L $^{-1}$. Although the response of infiltration to viscosity (and hydraulic conductivity) variations should be less-than-proportional, if viscosity were the only effect, a greater infiltration response would be expected. Although apparent viscosity is likely causing the infiltration decrease, viscosity alone cannot explain the measured effects.

When PAM was applied only during the initial phase of the irrigation, the PAM-induced infiltration reduction continued in the early phase (represented by the sorptivity coefficient), but the effect diminished at the end of the irrigation (final infiltration rate) for all concentrations. These results indicate that there was some carryover effect of the high PAM concentration in the soil pores that resist water flow. Allowing the soil to dry for $48 \mathrm{~h}$ after application of PAM (20 mm, 48-h delay) eliminated the PAM effect.

Previous studies found that applying $10 \mathrm{mg} \mathrm{PAM} \mathrm{L}^{-1}$ $\left(\sim 1 \mathrm{~kg}\right.$ PAM ha $\left.{ }^{-1}\right)$ to irrigation water in laboratory 
experiments (Levy et al., 1992) and in field plot studies (Trout et al., 1995; Flanagan et al., 1997; Lentz and Sojka, 2000b; Lentz et al., 2002) increased water infiltration rates. Most studies with PAM, however, were conducted on erosive soils that have low aggregate stability and on slopes that result in sediment transport and deposition. Under those conditions, PAM tends to increase infiltration by maintaining the integrity of aggregates and/or by preventing soil erosion and the formation of a depositional surface seal. Lentz and Sojka (2000a) reported that when soil structure had been destroyed by previous irrigation, PAM impact on infiltration depended on the PAM charge density and application sequence. Application of $10 \mathrm{mg} \mathrm{PAM} \mathrm{L} \mathrm{P}^{-1}$ as initial treatment (initial standard application) decreased infiltration but application of $10 \mathrm{mg} \mathrm{PAM} \mathrm{L}^{-1}$ of $100 \%$ charge density PAM or a continuous application of $0.25 \mathrm{mg}$ PAM L ${ }^{-1}$ of $18 \%$ charge density enhanced infiltration.

Results of this study indicate that the fluid properties of PAM solutions increase resistance to flow, which will result in reduced infiltration. Therefore, in order for PAM to increase infiltration, it must have a substantial effect on preserving or improving soil pore structure. Segeren and Trout (1991) calculated the hydraulic conductivity of the surface "seal" layer that forms in irrigation furrows in Portneuf silt loam soils. When soil erosion and sediment transport in the furrows were prevented, the conductivity of the soil surface layer was 10 to 100 times larger than when normal seal formation processes occurred. Preventing the seal formation resulted in a $100 \%$ increase in infiltration. In the same silt loam soil with similar measurement methods, Trout et al. (1995) measured a 30\% increase in infiltration with PAM. Thus, in erodible soils with sufficient fine-textured particles to form surface seals, it is feasible that soil structural changes can more than compensate for the PAM effect on viscosity.

In our previous field and recirculating infiltrometer trials (Trout and Ajwa, 2001), PAM did not increase infiltration rates on furrow-irrigated Hanford sandy loam soils when applied at $10 \mathrm{mg}$ PAM L L ${ }^{-1}$ or greater concentrations. Although Hanford soil aggregates break down with wetting and consolidate with wetting and drying to relatively high bulk densities $(1.5$ to $1.6 \mathrm{Mg}$ $\mathrm{m}^{-3}$ ), no visible depositional layer formed in this soil, and low permeability crusts or seals were not evident at the soil surface. These tests were performed in level furrows where flow velocity and shear and sediment transport tends to be low. Although effects of PAM in the water were visible (slightly clearer water, sediment flocs, and slightly rougher furrow perimeter soils following irrigation), these effects were evidently not adequate to sufficiently improve soil structure and result in increased infiltration. These results imply that surface crusting or sealing is not limiting infiltration under these conditions.

The effect of PAM on water viscosity presents an opportunity to improve water distribution in coarsetextured soils with high sustained infiltration rates. Surface irrigation distribution uniformity is often poor in these soils. If PAM reduces infiltration rates under these conditions, the water will advance more quickly across the field surface resulting in a more uniform irrigation and the potential for smaller water applications. Smaller water applications can result in reduced deep percolation loss of water and $\mathrm{N}$.

The $20 \mathrm{~mm}$ without delay treatment in the column tests showed a significant increase in infiltration with the addition of gypsum to DI water. Previous studies on the east side of the San Joaquin Valley, CA, have indicated that irrigation with canal water with very low EC results in soil dispersion. These soils have low salt content and low sodium adsorption ratios (Singer and Oster, 1984; Oster et al., 1992), and the addition of $\mathrm{Ca}$ to the canal water often results in improved infiltration. A common practice for growers using canal water in areas where soils have low infiltration rates is to add gypsum to the irrigation water. In field tests (Trout and Ajwa, 2001), infiltration with well water $\left(1.2 \mathrm{dS} \mathrm{m}^{-1}\right)$ was generally higher than with canal water, and infiltration using canal water improved with the addition of $3 \mathrm{mmol}_{\mathrm{c}} \mathrm{Ca} \mathrm{L}^{-1}$ as gypsum, but these effects were neither consistent nor large. The lack of significant response may be because soils at this farm were usually irrigated with well water and thus, contained higher salt levels than soils irrigated only with canal water.

Recently, Yu et al. (2003) reported that application of dry PAM (10-20 kg ha ${ }^{-1}$ ) plus gypsum (2-4 $\left.\mathrm{kg} \mathrm{ha}^{-1}\right)$ to soil increased final infiltration rate in silty loam soil by up to four times compared with the control (without gypsum). In our study, application of $\mathrm{Ca}$ to PAM solution reduced the negative effect of PAM on water infiltration (Table 6) by: (1) bridging and reducing the negatively charged sites of PAM, which caused PAM molecules to coil and form short chains that may be less effective in clogging the soil pores (Laird, 1997; Lentz, 2003; Yu et al., 2003), (2) reducing the solution viscosity (Table 1), and (3) increasing soil flocculation (Table 2). Although application of $\mathrm{NaCl}\left(\mathrm{SAR}_{9}\right.$ and $\left.\mathrm{SAR}_{18}\right)$ to PAM solution significantly reduced the relative viscosity, soil flocculation and water infiltration were not affected.

Earlier studies suggested that when anionic PAM is applied to dispersive soils, application of $\mathrm{Ca}$ to irrigation water would enhance PAM sorption to negatively charged soil surfaces and increase the effectiveness of PAM treatment (Lu et al., 2002). In our study, the effect of PAM on the sorptivity coefficient was greatly reduced with the high gypsum $\left(\mathrm{EC}_{1.5}\right)$ application to the anionic PAM solution, but this effect was small with the low gypsum $\left(\mathrm{EC}_{0.3}\right)$ rate or with $\mathrm{NaCl}$ solutions $\left(\mathrm{SAR}_{9}\right.$ and $\left.\mathrm{SAR}_{18}\right)$. It appears that $300 \mathrm{mg} \mathrm{Ca} \mathrm{L}^{-1}\left(15 \mathrm{mmol}_{\mathrm{c}} \mathrm{Ca} \mathrm{L}^{-1}\right)$ was sufficient to diminish the negative impact of $10 \mathrm{mg}$ $\mathrm{PAM} \mathrm{L}^{-1}$ on water infiltration into sandy loam soils. The effect of PAM on final infiltration rate was negligible $48 \mathrm{~h}$ after PAM application, indicating diminished viscosity effect. However, it appears that soil dispersion may have occurred in the $\mathrm{Na}$ and low $\mathrm{Ca}$ treatments, which resulted in a seal formation and reduced sorptivity coefficients.

\section{CONCLUSIONS}

Column infiltration studies demonstrated that PAMtreated water could reduce infiltration rates in San 
Joaquin Valley sandy loam soils by more than $50 \%$. The infiltration reduction was greater at high PAM concentrations, when PAM was applied continuously throughout the irrigation period, and in water with low salt or high $\mathrm{Na}$ content. The infiltration reduction was the result of a large increase in the apparent viscosity of PAM solutions. Calcium in the water reduced the impact of PAM on viscosity and infiltration. The PAM effect on infiltration was reduced when PAM was applied only during the initial stage of irrigation, and the effect was eliminated when PAM was applied as a pretreatment and allowed to dry before irrigation.

Although PAM has been shown to increase infiltration in some soils, our results show that infiltration improvement depends on improvement in aggregation and pore integrity and continuity sufficient to overcome the increased viscosity of the fluid. If there were little structural benefit, as was the case with Hanford sandy loam, infiltration would be expected to decrease. This viscosity effect of PAM may present an opportunity to improve surface irrigation water distribution uniformity in structureless and coarse-textured soils where infiltration rates are high and excessive water application is a problem.

\section{REFERENCES}

Ben-Hur, M., and Keren. 1997. Polymer effects on water infiltration and soil aggregation. Soil Sci. Soc. Am. J. 61:565-570.

Bjorneberg, D.L., and J.K. Aase. 2000. Multiple polyacrylamide applications for controlling sprinkler irrigation runoff and erosion. Appl. Eng. Agric. 16:501-504.

Bjorneberg, D.L., F.L. Santos, N.S. Castanheira, O.C. Martins, J.L. Reis, J.K. Aase, and R.E. Sojka. 2003. Using polyacrylamide with sprinkler irrigation to improve infiltration. J. Soil Water Conserv. 58:283-289.

Corey, A.T. 1977. Mechanics of heterogeneous fluids in porous media. Water Resources Publications, Ft. Collins, CO.

El-Morsy, E.A., M. Malik, and J. Letey. 1991a. Interactions between water quality and polymer treatment on infiltration rate and clay migration. Soil Technol. 4:221-231.

El-Morsy, E.A., M. Malik, and J. Letey. 1991b. Polymer effects on the hydraulic conductivity of saline and sodic soil conditions. Soil Sci. $151: 430-435$

Flanagan, D.C., L.D. Norton, and I. Shainberg. 1997. Effects of water chemistry and soil amendments on a silt loam soil-Part 1: Infiltration and runoff. Trans. ASAE 40:1549-1554.

Green, V.S., D.E. Stott, L.D. Norton, and J.G. Graveel. 2000. Polyacrylamide molecular weight and charge effects on infiltration under simulated rainfall. Soil Sci. Soc. Am. J. 64:1786-1791.

Laird, D.A. 1997. Bonding between polyacrylamide and clay mineral surfaces. Soil Sci. 162:826-832.

Lentz, R.D. 2003. Inhibiting water infiltration with polyacrylamide and surfactants: Applications for irrigated agriculture. J. Soil Water Conserv. 58:290-300.

Lentz, R.D., and R.E. Sojka. 1994. Field results using polyacrylamide to manage furrow erosion and infiltration. Soil Sci. 158:274-282.

Lentz, R.D., and R.E. Sojka. 2000a. Applying polymers to irrigation water: Evaluating strategies for furrow erosion control. Trans. ASAE 43:1561-1568.

Lentz, R.D., and R.E. Sojka. 2000b. Polymer charge and molecular weight effects on treated irrigation furrow processes. Int. J. Sediment Res. 15:17-30.
Lentz, R.D., I. Shainberg, R.E. Sojka, and D.L. Carter. 1992. Preventing irrigation furrow erosion with small applications of polymers. Soil Sci. Soc. Am. J. 56:1926-1932.

Lentz, R.D., R.E. Sojka, and B.E. Mackey. 2002. Fate and efficacy of polyacrylamide applied in furrow irrigation: Full-advance and continuous treatments. J. Environ. Qual. 31:661-670.

Levy, G.J., M. Ben-Hur, and M. Agassi. 1991. The effect of polyacrylamide on runoff, erosion, and cotton yield from fields irrigated with moving sprinkler systems. Irrig. Sci. 12:55-60.

Levy, G.J., J. Levin, M. Gal, M. Ben-Hur, and I. Shainberg. 1992. Polymers' effects on infiltration and soil erosion during consecutive simulated sprinkler irrigations. Soil Sci. Soc. Am. J. 56:902-907.

Lu, J.H., L. Wu, and J. Letey. 2002. Effect of soil and water properties on anionic polyacrylamides sorption. Soil Sci. Soc. Am. J. 66: $578-584$.

Malik, M., and J. Letey. 1992. Pore-size-dependent apparent viscosity for organic solutes in saturated porous media. Soil Sci. Soc. Am. J. 56:1032-1035.

McElhiney, M., and P. Osterli. 1996. An integrated approach for water quality: The PAM connection-West Stanislaus HUA, CA. p. 2730. In R.E. Sojka and R.D. Lentz (ed.) Proc.: Managing irrigationinduced erosion and infiltration with polyacrylamide. College of Southern Idaho, Twin Falls, ID. 6-8 May 1996. University of Idaho Misc. Publ. No. 101-96. University of Idaho, Twin Falls, ID.

Oster, J.D., M.J. Singer, A. Fulton, W. Richardson, and T. Prichard. 1992. Water penetration problems in California soils: Prevention, diagnoses, and solutions. Kearney Foundation of Soil Science, Univ. of California Div. of Agric. and Natural Resources. University of California, Riverside, CA.

Philip, J.R. 1957. The theory of infiltration: 4. Sorptivity and algebraic infiltration equation. Soil Sci. 84:257-264.

SAS Institute. 2000. SAS/Systat. SAS Institute, Inc., Cary, NC.

Segeren, A.G., and T.J. Trout. 1991. Hydraulic resistance of soil surface seals in irrigated furrows. Soil Sci. Soc. Am. J. 55:630-645.

Shainberg, I., D. Warrington, and P. Rengasamy. 1990. Effect of PAM and gypsum application on rain infiltration and runoff. Soil Sci. 149:301-307.

Singer, M.J., and J.D. Oster. 1984. Water penetration problems in California soils. Land, Air, and Water Resources Paper No. 10011, Dep. of Land, Air, and Water Resources, Univ. of Calif., Davis.

Sojka, R.E., R.D. Lentz, and D.T. Westermann. 1998a. Water and erosion management with multiple applications of polyacrylamide in furrow irrigation. Soil Sci. Soc. Am. J. 62:1672-1680.

Sojka, R.E., R.D. Lentz, C.W. Ross, T.J. Trout, D.L. Bjorneberg, and J.K. Aase. 1998b. Polyacrylamide effects on infiltration in irrigated agriculture. J. Soil Water Conserv. 53:325-331.

Trout, T.J., R.E. Sojka, and L.I. Okafor. 1990. Soil management. p. 897-896. In G.J. Hoffman et al. (ed.) Management of farm irrigation systems. ASAE, St. Joseph, MI.

Trout, T.J., R.E. Sojka, and R.D. Lentz. 1995. Polyacrylamide effect on furrow erosion and infiltration. Trans. ASAE 38:761-765.

Trout, T.J., and H. Ajwa. 2001. Polyacrylamide effects on infiltration in San Joaquin Valley sandy loam soils. Paper \#012259. 2001 ASAE Annual Meeting, Sacramento, CA. ASAE American Society of Agricultural and Biologyical Systems Engineers, St. Joseph, MI. Available online at http://asae.frymulti.com/abstract.asp?aid= 7401\& $\mathrm{t}=1$ (verified 23 Nov. 2005).

Wallace, A., and G.A. Wallace. 1996. Need for solution or exchangeable calcium and/or critical EC level for flocculation of clay by polyacryamides. p. 59-62. In R.E. Sojka and R.D. Lentz (ed.) Proc.: Managing irrigation-induced erosion and infiltration with polyacrylamide. College of Southern Idaho, Twin Falls, ID. 6-8 May 1996. University of Idaho Misc. Publ. No. 101-96. University of Idaho, Twin Falls, ID.

Yu, J., T. Lei, I. Shainberg, A.I. Mamedov, and G.J. Levy. 2003. Infiltration and Erosion in Soils Treated with Dry PAM and Gypsum. Soil Sci. Soc. Am. J. 67:630-636.

Zhang, X.C., and W.P. Miller. 1996. Polyacrylamide effect on infiltration and erosion in furrows. Soil Sci. Soc. Am. J. 60:866-872. 